4

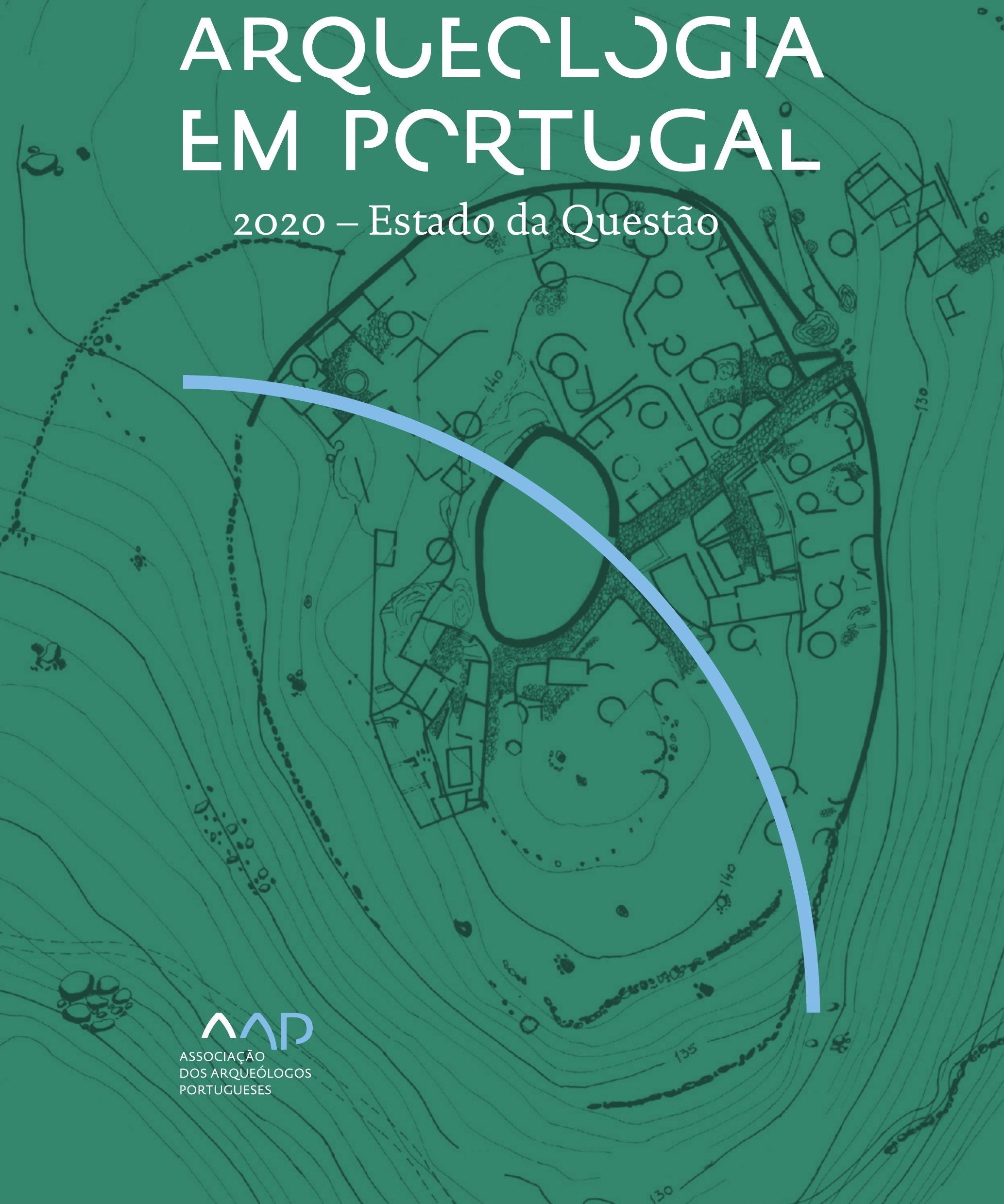


Coordenação editorial: José Morais Arnaud, César Neves e Andrea Martins Design gráfico: Flatland Design

AAP - ISBN: 978-972-9451-89-8

CITCEM - ISBN: 978-989-8970-25-1

Associação dos Arqueólogos Portugueses e CITCEM

Lisboa, 2020

O conteúdo dos artigos é da inteira responsabilidade dos autores. Sendo assim a Associação dos Arqueólogos Portugueses declina qualquer responsabilidade por eventuais equívocos ou questões de ordem ética e legal.

Desenho de capa:

Planta do castro de Monte Mozinho (Museu Municipal de Penafiel).

\section{$\hat{\wedge} \mathrm{P}$}

DOS ARQUEÓLOGOS PORTUGUESES

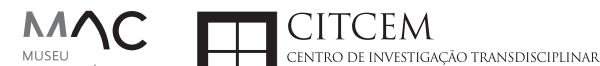
MUSEU
ARQUELLÓGICO
DO CARMO
U.PORTO

FLUP FACULDADE DE LETRAS
UNIVERSIDADE DO PORTO

Apoio

EC para a Ciência 


\section{Índice}

15 Prefácio

José Morais Arnaud

\section{Historiografia e Teoria}

17 Território, comunidade, memória e emoção: a contribuição da história da arqueologia (algumas primeiras e breves reflexões)

Ana Cristina Martins

25 Como descolonizar a arqueologia portuguesa?

Rui Gomes Coelho

41 Arqueologia e Modernidade: uma revisitação pessoal e breve de alguns aspetos da obra homónima de Julian Thomas de 2004

Vítor Oliveira Jorge

57 Dados para a História das Mulheres na Arqueologia portuguesa, dos finais do século XIX aos inícios do século XX: números, nomes e tabelas

Filipa Dimas / Mariana Diniz

73 Retractos da arqueologia portuguesa na imprensa: (in)visibilidades no feminino

Catarina Costeira / Elsa Luís

85 Arqueologia e Arqueólogos no Norte de Portugal Jacinta Bugalhão

101 Vieira Guimarães (1864-1939) e a arqueologia em Tomar: uma abordagem sobre o território e as gentes

João Amendoeira Peixoto / Ana Cristina Martins

115 Os memoráveis? A arqueologia algarvia na imprensa nacional e regional na presente centúria (2001-2019): características, visões do(s) passado(s) e a arqueologia

enquanto marca

Frederico Agosto / João Silva

129 A Evolução da Arqueologia Urbana e a Valorização Patrimonial no Barlavento Algarvio: Os casos de Portimão e Silves

Artur Mateus / Diogo Varandas / Rafael Boavida

\section{Gestão, Valorização e Salvaguarda do Património}

145 O Caderno Reivindicativo e as condições de trabalho em Arqueologia Miguel Rocha / Liliana Matias Carvalho / Regis Barbosa / Mauro Correia / Sara Simões / Jacinta Bugalhão / Sara Brito / Liliana Veríssimo Carvalho / Richard Peace / Pedro Peça / Cézer Santos

155 Os Estudos de Impacte Patrimonial como elemento para uma estratégia sustentável de minimização de impactes no âmbito de reconversões agrícolas Tiago do Pereiro

165 Salvaguarda de Património arqueológico em operações florestais: gestão e sensibilização Filipa Bragança / Gertrudes Zambujo / Sandra Lourenço / Belém Paiva / Carlos Banha / Frederico Tatá Regala / Helena Moura / Jacinta Bugalhão / João Marques / José Correia / Pedro Faria / Samuel Melro

179 Os valores do Património: uma investigação sobre os Sítios Pré-históricos de Arte Rupestre do Vale do Rio Côa e de Siega Verde José Paulo Francisco 
189 Conjugando recursos arqueológicos e naturais para potenciar as visitas ao Geoparque Litoral de Viana do Castelo (Noroeste de Portugal)

Hugo A. Sampaio / Ana M.S. Bettencourt / Susana Marinho / Ricardo Carvalhido

203 Áreas de Potencial Arqueológico na Região do Médio Tejo: Modelo Espacial Preditivo Rita Ferreira Anastácio / Ana Filipa Martins / Luiz Oosterbeek

223 Património Arqueológico e Gestão Territorial: O contributo da Arqueologia para a revisão do PDM de Avis

Ana Cristina Ribeiro

237 A coleção arqueológica do extinto Museu Municipal do Porto - Origens, Percursos e Estudos

Sónia Couto

251 Valpaços - uma nova carta arqueológica

Pedro Pereira / Maria de Fátima Casares Machado

263 Arqueologia na Cidade de Peniche

Adriano Constantino / Luís Rendeiro

273 Arqueologia Urbana: a cidade de Lagos como caso de Estudo Cátia Neto

285 Estratégias de promoção do património cultural subaquático nos Açores. O caso da ilha do Faial

José Luís Neto / José Bettencourt / Luís Borges / Pedro Parreira

297 Carta Arqueológica da Cidade Velha: Uma primeira abordagem

Jaylson Monteiro / Nireide Tavares / Sara da Veiga / Claudino Ramos / Edson Brito /

Carlos Carvalho / Francisco Moreira / Adalberto Tavares

311 Antropologia Virtual: novas metodologias para a análise morfológica e funcional Ricardo Miguel Godinho / Célia Gonçalves

\section{Didáctica da Arqueologia}

327 Como os projetos de Arqueologia podem contribuir para uma comunidade culturalmente mais consciente Alexandra Figueiredo / Claúdio Monteiro / Adolfo Silveira / Ricardo Lopes

337 Educação Patrimonial - Um cidadão esclarecido é um cidadão ativo! Ana Paula Almeida

351 A aproximação da Arqueologia à sala de aula: um caso de estudo no $3^{\circ}$ ciclo do Ensino Básico Luís Serrão Gil

363 Arqueologia 3.o - Pensar e comunicar a Arqueologia para um futuro sustentável Mónica Rolo

377 “Conversa de Arqueólogos" - Divulgar a Arqueologia em tempos de Pandemia Diogo Teixeira Dias

389 Escola Profissional de Arqueologia: desafios e oportunidades Susana Nunes / Dulcineia Pinto / Júlia Silva / Ana Mascarenhas

399 Os Museus de Arqueologia e os Jovens: a oferta educativa para o público adolescente Beatriz Correia Barata / Leonor Medeiros

411 O museu universitário como mediador entre a ciência e a sociedade: o exemplo da secção de arqueologia no Museu de História Natural e da Ciência da Universidade do Porto (MHNC-UP)

Rita Gaspar 
421 Museu de Lanifícios: Real Fábrica de Panos. Atividades no âmbito da Arqueologia Beatriz Correia Barata / Rita Salvado

427 Arqueologia Pública e o caso da localidade da Mata (Torres Novas) Cláudia Manso / Ana Rita Ferreira / Cristiana Ferreira / Vanessa Cardoso Antunes

431 Do sítio arqueológico ao museu: um percurso (também) didático Lídia Fernandes

447 Estão todos convidados para a Festa! E para dançar também... O projecto do Serviço Educativo do Museu Arqueológico do Carmo na $5^{\underline{a}}$ Edição da Festa da Arqueologia Rita Pires dos Santos

459 O “Clã de Carenque”, um projeto didático de arqueologia Eduardo Gonzalez Rocha

469 Mediação cultural: peixe que puxa carroça nas Ruínas Romanas de Troia Inês Vaz Pinto / Ana Patrícia Magalhães / Patrícia Brum / Filipa Santos

481 Didática Arqueológica, experiências do Projeto Mértola Vila Museu Maria de Fátima Palma / Clara Rodrigues / Susana Gómez / Lígia Rafael

\section{Arte Rupestre}

497 Os inventários de arte rupestre em Portugal Mila Simões de Abreu

513 O projeto FIRST-ART - conservação, documentação e gestão das primeiras manifestações de arte rupestre no Sudoeste da Península Ibérica: as grutas do Escoural e Maltravieso Sara Garcês / Hipólito Collado / José Julio García Arranz / Luiz Oosterbeek / António Carlos Silva / Pierluigi Rosina / Hugo Gomes / Anabela Borralheiro Pereira / George Nash / Esmeralda Gomes / Nelson Almeida / Carlos Carpetudo

523 Trabalhos de documentação de arte paleolítica realizados no âmbito do projeto PalæoCôa André Tomás Santos / António Fernando Barbosa / Luís Luís / Marcelo Silvestre / Thierry Aubry

537 Imagens fantasmagóricas, silhuetas elusivas: as figuras humanas na arte do Paleolítico Superior da região do Côa Mário Reis

$55^{1}$ Os motivos zoomórficos representados nas placas de tear de Vila Nova de São Pedro (Azambuja, Portugal) Andrea Martins / César Neves / José M. Arnaud / Mariana Diniz

571 Arte Rupestre do Monte de Góios (Lanhelas, Caminha). Síntese dos resultados dos trabalhos efectuados em 2007-2009 Mário Varela Gomes

599 Gravuras rupestres de barquiformes no Monte de S. Romão, Guimarães, Noroeste de Portugal Daniela Cardoso

613 Círculos segmentados gravados na Bacia do Rio Lima (Noroeste de Portugal): contributos para o seu estudo Diogo Marinho / Ana M.S. Bettencourt / Hugo Aluai Sampaio

631 Equídeos gravados no curso inferior do Rio Mouro, Monção (NW Portugal). Análise preliminar Coutinho, L.M. / Bettencourt, A.M.S / Sampaio, Hugo A.S

645 Paletas na Arte Rupestre do Noroeste de Portugal. Inventário preliminar Bruna Sousa Afonso / Ana M. S. Bettencourt / Hugo A. Sampaio 


\section{Pré-História}

661 O projeto Miño/Minho: balanço de quatro anos de trabalhos arqueológicos Sérgio Monteiro-Rodrigues / João Pedro Cunha-Ribeiro / Eduardo Méndez-Quintas / Carlos Ferreira / Pedro Xavier / José Meireles / Alberto Gomes / Manuel Santonja / Alfredo Pérez-González

677 A ocupação paleolítica da margem esquerda do Baixo Minho: a indústria lítica do sítio de Pedreiras 2 (Monção, Portugal) e a sua integração no contexto regional Carlos Ferreira / João Pedro Cunha-Ribeiro / Sérgio Monteiro-Rodrigues / Eduardo Méndez-Quintas / Pedro Xavier / José Meireles / Alberto Gomes / Manuel Santonja / Alfredo Pérez-González

693 O sítio acheulense do Plistocénico médio da Gruta da Aroeira Joan Daura / Montserrat Sanz / Filipa Rodrigues / Pedro Souto / João Zilhão

703 As sociedades neandertais no Barlavento algarvio: modelos preditivos com recurso aos SIG

Daniela Maio

715 A utilização de quartzo durante o Paleolítico Superior no território dos vales dos rios Vouga e Côa

Cristina Gameiro / Thierry Aubry / Bárbara Costa / Sérgio Gomes / Luís Luís / Carmen Manzano / André Tomás Santos

733 Uma perspetiva diacrónica da ocupação do concheiro do Cabeço da Amoreira (Muge, Portugal) a partir da tecnologia lítica Joana Belmiro / João Cascalheira / Célia Gonçalves

745 Novos dados sobre a Pré-história Antiga no concelho de Palmela. A intervenção arqueológica no sítio do Poceirão I

Michelle Teixeira Santos

757 Problemas em torno de Datas Absolutas Pré-Históricas no Norte do Alentejo Jorge de Oliveira

771 Povoamento pré-histórico nas áreas montanhosas do NO de Portugal: o Abrigo 1 de Vale de Cerdeira Pedro Xavier / José Meireles / Carlos Alves

783 Apreciação do povoamento do Neolítico Inicial na Baixa Bacia do Douro. A Lavra I (Serra da Aboboreira) como caso de estudo Maria de Jesus Sanches

797 O Processo de Neolitização na Plataforma do Mondego: os dados do Sector C do Outeiro dos Castelos de Beijós (Carregal do Sal)

João Carlos de Senna-Martinez / José Manuel Quintã Ventura / Andreia Carvalho / Cíntia Maurício

823 Novos trabalhos na Lapa da Bugalheira (Almonda, Torres Novas) Filipa Rodrigues / Pedro Souto / Artur Ferreira / Alexandre Varanda / Luís Gomes / Helena Gomes / João Zilhão

837 A pedra polida e afeiçoada do sítio do Neolítico médio da Moita do Ourives (Benavente, Portugal)

César Neves

857 Casal do Outeiro (Encarnação, Mafra): novos contributos para o conhecimento do povoamento do Neolítico final na Península de Lisboa.

Cátia Delicado / Carlos Maneira e Costa / Marta Miranda / Ana Catarina Sousa

873 Stresse infantil, morbilidade e mortalidade no sítio arqueológico do Neolítico Final/ Calcolítico ( $4^{\circ}$ e $3^{\circ}$ milénio a.C.) do Monte do Carrascal 2 (Ferreira do Alentejo, Beja) Liliana Matias de Carvalho / Sofia N. Wasterlain 
885 Come together: O Conjunto Megalítico das Motas (Monção, Viana do Castelo) e as expressões Campaniformes do Alto Minho Ana Catarina Basílio / Rui Ramos

899 Trabalhos arqueológicos no sítio Calcolítico da Pedreira do Poio Carla Magalhães / João Muralha / Mário Reis / António Batarda Fernandes

913 O sítio arqueológico de Castanheiro do Vento. Da arquitectura do sítio à arquitectura de um território João Muralha Cardoso

925 Estudo zooarqueológico das faunas do Calcolítico final de Vila Nova de São Pedro (Azambuja, Portugal): Campanhas de 2017 e 2018 Cleia Detry / Ana Catarina Francisco / Mariana Diniz / Andrea Martins / César Neves / José Morais Arnaud

943 As faunas depositadas no Museu Arqueológico do Carmo provenientes de Vila Nova de São Pedro (Azambuja): as campanhas de 1937 a 1967 Ana Catarina Francisco / Cleia Detry / César Neves / Andrea Martins / Mariana Diniz / José Morais Arnaud

959 Análise funcional de material lítico em sílex do castro de Vila Nova de S. Pedro (Azambuja, Portugal): uma primeira abordagem Rafael Lima

971 O recinto da Folha do Ouro 1 (Serpa) no contexto dos recintos de fossos calcolíticos alentejanos

António Carlos Valera / Tiago do Pereiro / Pedro Valério / António M. Monge Soares

\section{Proto-História}

987 Produção de sal marinho na Idade do Bronze do noroeste Português. Alguns dados para uma reflexão

Ana M. S. Bettencourt / Sara Luz / Nuno Oliveira / Pedro P. Simões / Maria Isabel C. Alves / Emílio Abad-Vidal

1001 A estátua-menir do Pedrão ou de São Bartolomeu do Mar (Esposende, noroeste de Portugal) no contexto arqueológico da fachada costeira de entre os rios Neiva e Cávado Ana M. S. Bettencourt / Manuel Santos-Estévez / Pedro Pimenta Simões / Luís Gonçalves

1015 O Castro do Muro (Vandoma/Baltar, Paredes) - notas para uma biografia de ocupação da Idade do Bronze à Idade Média

Maria Antónia D. Silva / Ana M. S. Bettencourt / António Manuel S. P. Silva / Natália Félix

1031 Do Bronze Final à Idade Média - continuidades e hiatos na ocupação de Povoados em Oliveira de Azeméis João Tiago Tavares / Adriaan de Man

1041 As faunas do final da Idade do Bronze no Sul de Portugal: leituras desde o Outeiro do Circo (Beja)

Nelson J. Almeida / Íris Dias / Cleia Detry / Eduardo Porfírio / Miguel Serra

1055 A Espada do Monte das Oliveiras (Serpa) - uma arma do Bronze Pleno do Sudoeste Rui M. G. Monge Soares / Pedro Valério / Mariana Nabais / António M. Monge Soares

1065 São Julião da Branca (Albergaria-a-Velha) - Investigação e valorização de um povoado do Bronze Final

António Manuel S. P. Silva / Paulo A. P. Lemos / Sara Almeida e Silva / Edite Martins de Sá

1083 Do castro de S. João ao Mosteiro de Santa Clara: notícia de uma intervenção arqueológica, em Vila do Conde Rui Pinheiro 
1095 O castro de Ovil (Espinho), um quarto de século de investigação - resultados e questões em aberto

Jorge Fernando Salvador / António Manuel S. P. Silva

1111 O Castro de Salreu (Estarreja), um povoado proto-histórico no litoral do Entre Douro e Vouga

Sara Almeida e Silva / António Manuel S. P. Silva / Paulo A. P. Lemos / Edite Martins de Sá

1127 Castro de Nossa Senhora das Necessidades (Sernancelhe): uma primeira análise artefactual Telma Susana O. Ribeiro

${ }_{1141}$ A cividade de Bagunte. O estado atual da investigação Pedro Brochado de Almeida

1153 Zoomorfos na cerâmica da Idade do Ferro no NW Peninsular: inventário, cronologias e significado Nuno Oliveira / Cristina Seoane

1163 Vasos gregos em Portugal: diferentes maneiras de contar a história do intercâmbio cultural na Idade do Ferro

Daniela Ferreira

1175 Os exotica da necrópole da Idade do Ferro do Olival do Senhor dos Mártires (Alcácer do Sal) no seu contexto regional

Francisco B. Gomes

\section{Antiguidade Clássica e Tardia}

1191 O uso de madeira como combustível no sítio da Quinta de Crestelos (Baixo Sabor): da Idade do Ferro à Romanização Filipe Vaz / João Tereso / Sérgio Simões Pereira / José Sastre / Javier Larrazabal Galarza / Susana Cosme / José António Pereira / Israel Espi

1207 Cultivos de Época Romana no Baixo Sabor: continuidade em tempos de mudança? João Pedro Tereso / Sérgio Simões Pereira / Filipe Santos / Luís Seabra / Filipe Vaz

1221 A casa romana na Hispânia: aplicação dos modelos itálicos nas províncias ibéricas Fernanda Magalhães / Diego Machado / Manuela Martins

1235 As pinturas murais romanas da Rua General Sousa Machado, n. ${ }^{5}$ 1, Chaves José Carvalho

1243 Trás do Castelo (Vale de Mir, Pegarinhos, Alijó) - Uma exploração agrícola romana do Douro

Tony Silvino / Pedro Pereira

1255 A sequência de ocupação no quadrante sudeste de Bracara Augusta: as transformações de uma unidade doméstica Lara Fernandes / Manuela Martins

1263 Os Mosaicos com decoração geométrica e geométrico-vegetalista dos sítios arqueológicos da área do Conuentus Bracaraugustanus. Novas abordagens quanto à conservação, restauro, decoração e datação Maria de Fátima Abraços / Licínia Wrench

1277 “Casa Romana” do Castro de São Domingos (Cristelos, Lousada): Escavação, Estudo e Musealização Paulo André de P. Lemos

1291 A arqueobotânica no Castro de Guifões (Matosinhos, Noroeste de Portugal): O primeiro estudo carpológico

Luís Seabra / Andreia Arezes / Catarina Magalhães / José Varela / João Pedro Tereso 
1305 Um Horreum Augustano na Foz do Douro (Monte do Castelo de Gaia, Vila Nova de Gaia) Rui Ramos

1311 Ponderais romanos na Lusitânia: padrões, formas, materiais e contextos de utilização Diego Barrios Rodríguez

1323 Um almofariz centro-itálico na foz do Mondego

Marco Penajoia

1335 Estruturas romanas de Carnide - Lisboa Luísa Batalha / Mário Monteiro / Guilherme Cardoso

1347 O contexto funerário do sector da "necrópole NO" da Rua das Portas de S. Antão (Lisboa): o espaço, os artefactos, os indivíduos e a sua interconectividade na interpretação do passado Sílvia Loja, José Carlos Quaresma, Nelson Cabaço, Marina Lourenço, Sílvia Casimiro, Rodrigo Banha da Silva, Francisca Alves-Cardoso

${ }_{1361}$ Povoamento em época Romana na Amadora - resultados de um projeto pluridisciplinar Gisela Encarnação / Vanessa Dias

1371 A Arquitectura Residencial em Mirobriga (Santiago do Cacém): contributo a partir de um estudo de caso Filipe Sousa / Catarina Felício

${ }_{1385}$ O fim do ciclo. Saneamento e gestão de resíduos nos edifícios termais de Mirobriga (Santiago do Cacém)

Catarina Felício / Filipe Sousa

1399 Balsa, Topografia e Urbanismo de uma Cidade Portuária Vítor Silva Dias / João Pedro Bernardes / Celso Candeias / Cristina Tété Garcia

1413 No Largo das Mouras Velhas em Faro (2017): novas evidências da necrópole norte de Ossonoba e da sua ocupação medieval Ricardo Costeira da Silva / Paulo Botelho / Fernando Santos / Liliana Nunes

1429 Instrumentos de pesca recuperados numa fábrica de salga em Ossonoba (Faro) Inês Rasteiro / Ricardo Costeira da Silva / Paulo Botelho

1439 A Necrópole Romana do Eirô, Duas Igrejas (Penafiel): intervenção arqueológica de 2016 Laura Sousa / Teresa Soeiro

1457 Ritual, descarte ou afetividade? A presença de Canis lupus familiaris na Necrópole Noroeste de Olisipo (Lisboa)

Beatriz Calapez Santos / Sofia Simões Pereira / Rodrigo Banha da Silva / Sílvia Casimiro / Cleia Detry / Francisca Alves Cardoso

1467 Dinâmicas económicas em Bracara na Antiguidade Tardia Diego Machado / Manuela Martins / Fernanda Magalhães / Natália Botica

1479 Cerâmicas e Vidros da Antiguidade Tardia do Edifício sob a Igreja do Bom Jesus (Vila Nova de Gaia) Joaquim Filipe Ramos

1493 Novos contributos para a topografia histórica de Mértola no período romano e na Antiguidade Tardia Virgílio Lopes

\section{8. Época Medieval}

1511 Cerâmicas islâmicas no Garb setentrional "português": algumas evidências e incógnitas Constança dos Santos / Helena Catarino / Susana Gómez / Maria José Gonçalves / Isabel Inácio / Gonçalo Lopes / Jacinta Bugalhão / Sandra Cavaco / Jaquelina Covaneiro / Isabel Cristina Fernandes / Ana Sofia Gomes 
1525 Contributo para o conhecimento da cosmética islâmica, em Silves, durante a Idade Média Rosa Varela Gomes

1537 Yábura e o seu território - uma análise histórico-arqueológica de Évora entre os séculos VIII-XII José Rui Santos

1547 A encosta sul do Castelo de Palmela - resultados preliminares da escavação arqueológica Luís Filipe Pereira / Michelle Teixeira Santos

1559 A igreja de São Lourenço (Mouraria, Lisboa): um conjunto de silos e de cerâmica medieval islâmica

Andreia Filipa Moreira Rodrigues

1571 O registo material de movimentações populacionais no Médio Tejo, durante os séculos XII-XIII. Dois casos de "sunken featured buildings", nos concelhos de Cartaxo e Torres Novas Marco Liberato / Helena Santos / Nuno Santos

1585 O nordeste transmontano nos alvores da Idade média. Notas para reflexão Ana Maria da Costa Oliveira

1601 Sepulturas escavadas na rocha do Norte de Portugal e do Vale do Douro: primeiros resultados do Projecto SER-NPVD

Mário Jorge Barroca / César Guedes / Andreia Arezes / Ana Maria Oliveira

1619 "Portucalem Castrum Novum" entre o Mediterrâneo e o Atlântico: o estudo dos materiais cerâmicos alto-medievais do arqueossítio da rua de D. Hugo, nํ. 5 (Porto) João Luís Veloso

1627 A Alta Idade Média na fronteira de Lafões: notas preliminares sobre a Arqueologia no Concelho de Vouzela

Manuel Luís Real / Catarina Tente

1641 Um conjunto cerâmico medieval fora de portas: um breve testemunho aveirense Susana Temudo

${ }_{1651}$ Os Lóios do Porto: uma perspetiva integrada no panorama funerário da Baixa Idade Média à Época Moderna em meios urbanos em Portugal

Ana Lema Seabra

1659 O Caminho Português Interior de Santiago como eixo viário na Idade Média Pedro Azevedo

1665 Morfologia Urbana: Um exercício em torno do Castelo de Ourém André Donas-Botto / Jaqueline Pereira

1677 Intervenção arqueológica na Rua Marquês de Pombal/Largo do Espírito Santo (Bucelas, Loures)

Florbela Estêvão / Nathalie Antunes-Ferreira / Dário Ramos Neves / Inês Lisboa

1691 O Cemitério Medieval do Poço do Borratém e a espacialidade funerária na cidade de Lisboa Inês Belém / Vanessa Filipe / Vasco Noronha Vieira / Sónia Ferro / Rodrigo Banha da Silva

1705 Um Espaço Funerário Conventual do séc. XV em Lisboa: o caso do Convento de São Domingos da Cidade Sérgio Pedroso / Sílvia Casimiro / Rodrigo Banha da Silva / Francisca Alves Cardoso

\section{9. Época Moderna e Contemporânea}

1721 Arqueologia Moderna em Portugal: algumas reflexões críticas em torno da quantificação de conjuntos cerâmicos e suas inferências históricas e antropológicas Rodrigo Banha da Silva / André Bargão / Sara da Cruz Ferreira

1733 Faianças de dois contextos entre os finais do século XVI e XVIII do Palácio dos Condes de Penafiel, Lisboa

Martim Lopes / Tomás Mesquita 
1747 Um perfil de consumo do século XVIII na foz do Tejo: O caso do Mercado da Ribeira, Lisboa Sara da Cruz Ferreira / Rodrigo Banha da Silva / André Bargão

1761 Os Cachimbos dos Séculos XVII e XVIII do Palácio Mesquitela e Convento dos Inglesinhos (Lisboa)

Inês Simão / Marina Pinto / João Pimenta / Sara da Cruz Ferreira / André Bargão / Rodrigo Banha da Silva

1775 "Tomar os fumos da erua que chamão em Portugal erua sancta». Estudo de Cachimbos provenientes da Rua do Terreiro do Trigo, Lisboa

Miguel Martins de Sousa / José Pedro Henriques / Vanessa Galiza Filipe

1787 Cachimbos de Barro Caulínitico da Sé da Cidade Velha (República de Cabo Verde)

Rodrigo Banha da Silva / João Pimenta / Clementino Amaro

1801 Algumas considerações sobre espólio não cerâmico recuperado no Largo de Jesus (Lisboa) Carlos Boavida

1815 Adereços de vidro, dos séculos XVI-XVIII, procedentes do antigo Convento de Santana de Lisboa (anéis, braceletes e contas)

Joana Gonçalves / Rosa Varela Gomes / Mário Varela Gomes

1837 Da ostentação, luxo e poder à simplicidade do uso quotidiano: arqueologia e simbologia de joias e adornos da Idade Moderna Portuguesa Jéssica Iglésias

1849 Os amuletos em Portugal - dos objetos às superstições: o coral vermelho Alexandra Vieira

1865 Cerâmicas de Vila Franca de Xira nos séculos XV e XVI Eva Pires

1879 «Não passa por teu o que me pertence». Marcas de individualização associadas a faianças do Convento de Nossa Senhora de Aracoeli, Alcácer do Sal Catarina Parreira / Íris Fragoso / Miguel Martins de Sousa

1891 Cerâmica de Leiria: alguns focos de produção

Jaqueline Pereira / André Donas-Botto

1901 Os Fornos na Rua da Biquinha, em Óbidos Hugo Silva / Filipe Oliveira

1909 A casa de Pêro Fernandes, contador dos contos de D. Manuel I: o sítio arqueológico da Silha do Alferes, Seixal (século XVI) Mariana Nunes Ferreira

1921 O Alto da Vigia (Sintra) e a vigilância e defesa da costa Alexandre Gonçalves / Sandra Santos

1937 O contexto da torre sineira da Igreja de Santa Maria de Loures Paulo Calaveira / Martim Lopes

1949 A Necrópole do Hospital Militar do Castelo de São Jorge e as práticas funerárias na Lisboa de Época Moderna Susana Henriques / Liliana Matias de Carvalho / Ana Amarante / Sofia N. Wasterlain

1963 SAND - Sarilhos Grandes Entre dois Mundos: o adro da Igreja e a Paleobiologia dos ossos humanos recuperados

Paula Alves Pereira / Roger Lee Jesus / Bruno M. Magalhães

1975 Expansão urbana da vila de Cascais no século XVII e XVIII: a intervenção arqueológica na Rua da Vitória no 15 a 17

Tiago Pereira / Vanessa Filipe

1987 Novos dados para o conhecimento do Urbanismo de Faro em época Moderna Ana Rosa 
1995 Um exemplo de Arqueologia Urbana em Alcoutim: o Antigo Edifício dos CTT Marco Fernandes / Marta Dias / Alexandra Gradim / Virgílio Lopes / Susana Gómez Martínez

2007 Palácio dos Ferrazes (Rua das Flores/Rua da Vitória, Porto): a cocheira de Domingos Oliveira Maia

Francisco Raimundo

2021 As muitas vidas de um edifício urbano: História, Arqueologia e Antropologia no antigo Recreatório Paroquial de Penafiel Helena Bernardo / Jorge Sampaio / Marta Borges

2035 O convento de Nossa Senhora da Esperança de Ponta Delgada: o contributo da arqueologia para o conhecimento de um monumento identitário João Gonçalves Araújo / N’Zinga Oliveira

2047 Arqueologia na ilha do Corvo... em busca da capela de Nossa Senhora do Rosário Tânia Manuel Casimiro / José Luís Neto / Luís Borges / Pedro Parreira

2059 Perdidos à vista da Costa. Trabalhos arqueológicos subaquáticos na Barra do Tejo Jorge Freire / José Bettencourt / Augusto Salgado

2071 Arqueologia marítima em Cabo Verde: enquadramento e primeiros resultados do projecto CONCHA

José Bettencourt / Adilson Dias / Carlos Lima / Christelle Chouzenoux / Cristóvão Fonseca / Dúnia Pereira / Gonçalo Lopes / Inês Coelho / Jaylson Monteiro / José Lima / Maria Eugénia Alves / Patrícia Carvalho / Tiago Silva

2085 Trabalhos arqueológicos na Cidade Velha (Ribeira Grande de Santiago, Cabo Verde): reflexões sobre um projecto de investigação e divulgação patrimonial André Teixeira / Jaylson Monteiro / Mariana Mateus / Nireide Tavares / Cristovão Fonseca / Gonçalo C. Lopes / Joana Bento Torres / Dúnia Pereira / André Bargão / Aurélie Mayer / Bruno Zélie / Carlos Lima / Christelle Chouzenoux / Inês Henriques / Inês Pinto Coelho / José Lima / Patrícia Carvalho / Tiago Silva

2103 A antiga fortificação de Quelba / Khor Kalba (E.A.U.). Resultados de quatro campanhas de escavações, problemáticas e perspectivas futuras Rui Carita / Rosa Varela Gomes / Mário Varela Gomes / Kamyar Kamyad

2123 Colónias para homens novos: arqueologia da colonização agrária fascista no noroeste ibérico Xurxo Ayán Vila / José Mạ . Señorán Martín 


\title{
O CONTEXTO FUNERÁRIO DO SECTOR DA “NECRÓPOLE NO"DA RUA DAS PORTAS DE S. ANTÃO (LISBOA): O ESPAÇO, OS ARTEFACTOS, OS INDIVÍDUOS E A SUA INTERCONECTIVIDADE NA INTERPRETAÇÃO DO PASSADO
}

\author{
Sílvia Loja ${ }^{1}$, José Carlos Quaresma ${ }^{2}$, Nelson Cabaço ${ }^{3}$, Marina Lourenço ${ }^{4}$, Sílvia Casimiro ${ }^{5}$, \\ Rodrigo Banha da Silva ${ }^{6}$, Francisca Alves-Cardoso ${ }^{7}$
}

\begin{abstract}
RESUMO
A intervenção arqueológica da Rua das Portas de Santo Antão, em Lisboa, revelou uma extensa diacronia, com vestígios situados cronologicamente entre a Idade do Bronze Final e a Época Contemporânea, destacando-se as evidências associadas ao uso do espaço enquanto local funerário durante a Época Romana Imperial. A área, tirando proveito de uma antiga e pequena plataforma natural situada no sopé da Encosta de Sant 'Ana, encontrava-se decerto próxima ao trajecto da "Via Norte" de Olisipo, o principal eixo das comunicações terrestres da cidade, integrando por este motivo a designada "Necrópole NO". O presente trabalho procede ao estudo do contexto funerário, expondo-se em articulação os dados contextuais, os estudos artefactual e bioantropológico, visando uma interpretação compreensiva do núcleo funerário.

Palavras-chave: Arqueologia Romana, Arqueologia Funerária Romana, Sigillata Clara Africana, Vidro, Cerâmica Romana.
\end{abstract}

\section{ABSTRACT}

The archaeological intervention of Rua das Portas de Santo Antão, in Lisbon, revealed an extensive diachrony, with archaeological findings dating chronologically between the Late Bronze Age and the Contemporary Period. The findings associated with the use of the space as a funerary site, during the Roman Imperial Period deserve special attention. The area, taking advantage of an old and small natural platform located in the foothills of the Encosta de Sant 'Ana, was certainly close to Olisipo's “Via Norte”, the main axis of the city's land communications, integrating for this reason the so-called "Necropolis NO". This paper presents the funerary context, articulating the contextual, artefactual and bioanthropological data, aiming at a comprehensive interpretation of this burial ground.

Keywords: Roman Archaeology, Roman funerary archaeology, Bioanthropology, Roman Glass, Roman Pottery.

1. NOVA FCSH; Mestranda em Arqueologia; Laboratório de Antropologia Biológica e Osteologia Humana, Centro em Rede de Investigação em Antropologia (LABOH-CRIA); silvialoja@hotmail.com

2. Departamento de História NOVA FCSH. Instituto de Estudos Medievais, IEM NOVA FCSH; josecarlosquaresma@gmail.com

3. Era-Arqueologia.nelsoncabaco@era-arqueologia.pt

4. Era-Arqueologia.marinalourenco@era-arqueologia.pt

5. Instituto de Estudos Medievais, IEM NOVA FCSH, Laboratório de Antropologia Biológica e Osteologia Humana, Centro em Rede de Investigação em Antropologia (LABOH-CRIA), NOVA FCSH; scasimiro@fcsh.unl.pt

6. CAL/DPC/CML. Departamento de História NOVA FCSH; Centro de humanidades, CHAM NOVA FCSH; rbds@fcsh.unl.pt 7. Laboratório de Antropologia Biológica e Osteologia Humana, Centro em Rede de Investigação em Antropologia (LABOH-CRIA), NOVA FCSH; Cranfield Defense \& Security, Cranfield University, Reino Unido; francicard@fcsh.unl.pt 


\section{INTRODUÇÃO}

O núcleo funerário romano escavado no prédio com os n. ㅇs 84-9o da Rua das Portas de Santo Antão, em Lisboa, foi primeiro apresentado no II Congresso da Associação dos Arqueólogos Portugueses (Cabaço \& alii, 2017a) tendo-se, entretanto, também divulgado um compasso com aquela cronologia (Cabaço \& alii, 2019). Conforme foi descrito antes, remetendo-se o leitor para a bibliografia aí cotejada, o espaço equivale a um núcleo da Necrópole NO da cidade (Cabaço \& alii, 2017a; 2019), designação cunhada por um dos autores, inspirada em modelos de estudo urbanístico de cidades romanas peninsulares (Silva, 2005).

\section{OS DADOS DO NÚCLEO DAS PORTAS DE SANTO ANTÃO}

Conforme já antes notado, assinala-se no núcleo de "Portas de Santo Antão, uma homogeneidade mais do que relativa nas práticas funerárias documentadas, onde o ritual de inumação era exclusivo, e o uso do esquife recorrente" (Cabaço \& alii, 2017a, p. 1248). A relativa sincronia das práticas documentadas no local, atestada pelas cronologias dos elementos da cultura material associados e que nos colocam as acções fúnebres dentro do séc. III d.C., é também sugerida pela própria gestão do espaço: não se verificaram sobreposições/afectações das sepulturas por outras posteriores, havendo uma relativa "organização" das dinâmicas, patente na orientação dos vários episódios fúnebres, o que implica que por diversas formas se assinalou a visibilidade da existência dos sepultamentos, nalguns casos ainda preservada no momento da escavação arqueológica. Articulam-se aqui os dados contextuais, artefactuais e bioantropológicos, visando uma interpretação compreensiva do núcleo no seu todo, destacando os aspectos mais relevantes evidenciados até ao momento pelos estudos ainda em curso.

\section{ABORDAGEM METODOLÓGICA DA ANÁLISE DOS DADOS}

A abordagem combina a informação presente na documentação da intervenção, a análise do mobiliário funerário, de modo a afinar a informação crono-tipológica, e a análise bioantropológica obtida em laboratório. Esta incidiu na determinação do perfil biológico dos indivíduos, e.g. diagnose sexual e a es- timativa da idade à morte, e outros indicadores morfológicos quando possível. A diagnose sexual foi aferida apenas nos indivíduos adultos, uma vez que estimativa do sexo em indivíduos cuja maturidade é incipiente incorre em significativos erros interpretativos (Cardoso \& Saunders, 2008). Para aferir a diagnose sexual, foram empregues vários métodos que evidenciam o dimorfismo sexual, com base na análise morfológica e métrica do material ósseo (Bruzek, 2002; Buikstra \& Ubelaker, 1994; Ferembach, Schwidetzky \& Stloukal, 1980; Lovejoy \& alii, 1985; Walker, 2005, 2008; Wasterlain, 200o), sendo os vários indivíduos classificados de feminino, masculino, ou de sexo indeterminado com base nos resultados das análises. Para a estimativa da idade à morte foi considerado o critério da fusão das epífises utilizando-se diversos métodos de acordo com os elementos ósseos a avaliar (Buikstra \& Ubelaker, 1994; MacLaughlin, 1990; White \& Folkens, 2005). Com base na análise desenvolvida os indivíduos foram classificados de adultos (provavelmente com $>30$ anos) e adulto jovem (provavelmente com $>18$ anos mas $<30$ anos), sobretudo com base no estágio de maturação epifisária da extremidade esternal da clavícula (MacLaughlin, 1990). Alguns indivíduos foram ainda identificados como não adultos, atribuindo-se um intervalo etário mais específico como complemento da estimativa qualitativa. Para cada sepultura são apresentados os dados relativos às características construtivas, dados da bioantropologia, características e cronologias do mobiliário funerário e sua disposição (Figura 1).

Sepultura 1 - Sepultura com deposição de ataúde documentado por pregos em ferro- (Cabaço $\mathbb{\&}$ alii, 2017a: fig.3) no interior de coval. Cobertura exterior não passível de identificação dadas as afectações posteriores.

Bioantropologia: esqueleto em mau estado de conservação, inumado em decúbito dorsal com os membros superiores e inferiores em extensão. Estimou tratar-se de um indivíduo adulto, do sexo masculino (Buikstra \& Ubelaker, 1994; Bruzek, 2002; Walker, 2005), com mais de 30 anos com base no estágio de fusão epifisária da extremidade esternal da clavícula (MacLaughlin, 1990).

"Mobiliário funerário": Para além do numisma no 172, um antoninianus inclassificável, a sep. 1 apresenta um espólio de terra sigillata, lucerna, vidro e cerâmica comum. O no 174 é um prato em T.S.Cl.Afr. 
C, do tipo Hayes 50A/B, com proximidade grande à variante $5 \mathrm{OB}$ (quase $5 \mathrm{~mm}$ de espessura, parede esvasada e bordo de topo arredondado - Hayes 1972). $\mathrm{O}$ vidro $\mathrm{n}^{\mathbf{0}} \mathbf{1 7 0}$ pode integrar-se, como basicamente todos os vidros presentes neste conjunto de sepulturas, no tipo AR 6o, com pé-de-anel denteado, datável a partir de 250 d.C. (Rütti, 1991). A lucerna no 171, sobremoldada, de grande porte (diâmetro de $108 \mathrm{~mm}$ ), poderá integrar-se no universo das lucernas de disco, embora apresente um canal que a relaciona com as Firmalampen, coevas das primeiras, entre os sécs. I e III d.C. (Quaresma, no prelo). Com um disco e ombro planos, apresenta uma Victoria frontal com disco na mão direita (Rodríguez Martín, 2002). Por fim, o no 173 é uma pequena bilha de cerâmica comum em pasta branca de matriz calcária, com colo estreito e canelura larga, à altura do arranque da asa. Não tem paralelo no centro produtor da Quinta do Rouxinol, onde este fabrico está diagnosticado (Santos, 2011), nem em São Cucufate (Pinto, 2003), mas exemplares semelhantes surgem nas necrópoles do Alto-Alentejo (Nolen, 1985, p. 42, 43, no 39: pasta $\mathrm{H}_{2}$ - pasta branca-ocre) e em Conimbriga, em depósito de Trajano (Alarcão, 1975, ํㅜ5 586).

Sepultura 2 - Deposição de ataúde no interior de coval, denunciado pela presença de elementos da pregaria.

Bioantropologia: o esqueleto encontrava-se muito frágil, em mau estado de conservação, e a sua metade superior muito afectada. Depositado em decúbito dorsal com os membros superiores ligeiramente flectidos sobre o abdómen, as mãos sobre a zona pélvica e os membros inferiores em extensão. Trata-se de um indivíduo do sexo feminino (Wasterlain, 2000; Bruzek, 2002; Walker, 2005). A avaliar pela morfologia da superfície auricular, parece tratar-se de um adulto ainda jovem (Lovejoy $\&$ alii, 1985).

"Mobiliário funerário": A sepultura 2 apresenta um anel, uma lucerna, dois vidros e cerâmica comum. O anel de prata no 196 mostra simulação de pedra de sinete feita no mesmo material, e é equivalente ao tipo IVc de Aquincum, morfologia ali do séc. III d.C. e que sobreviveria ao longo do séc. IV d.C. (Facsády \& Verebes, 2009: 994, fig.1; 997). Voltamos a registar vidros na gama do tipo AR 6o, mas evidenciando a sua diversidade morfológica e a necessidade de uma melhor especificação deste tipo em vários. Assim, o no 197 apresenta as depressões oblongas verticais, mas fundo agora onfalado, enquanto $o$ no 196 apresenta a parede lisa, mas o fundo maciço. Este último apresenta-se agora mais próximo do descritório de copos de paredes finas e base maciça, relacionados também com a Isings 34, datáveis entre os séc.s II e IV (Cruz, 2009, p. 91). A lucerna no 196 também se inclui na morfologia do séc. III, referida supra para a família de lucernas de disco, com moldura larga, ombro oblíquo curvo e disco curvo também (Quaresma, 2018). Na cerâmica comum, o no 200 é um jarro de bordo extrovertido, curto e não-trilobado, de fabrico quartzo-micáceo, castanho-claro-laranja, com parede curva, lisa e ligeira semelhança com o tipo XI-A de São Cucufate, em fabrico calcário bético, mais esguio e estreito do que o de Olisipo. No centro produtor sadino do Pinheiro, surge uma morfologia semelhante, em camada da segunda metade do séc. IV (Pinto, 2003, p. 425). O no 199 é uma taça de fundo maciço, em pasta quartzo-micácea avermelhada, cuja fisionomia da parede e bordo em aba a inclui nas inspirações da Hayes 3 de terra sigillata africana A, datável nos séc.s II e III d.C. (Hayes, 1972). Por fim, o no 201 é um pote baixo de bordo curto exvertido e pasta laranja, quartzo-micácea. Como referimos supra, os potes do Norte Alentejano são sempre gráceis, mas com semelhanças formais (Nolen, 1985, p. 118).

Sepultura 3-Deposição em coval de secção rectangular. Assinalando a visibilidade do sepultamento foi composta uma cobertura primária de 4 lateres recobertos por elementos pétreos e laterícios fragmentários de pequena dimensão, unidos com uma argamassa pobre, dispostos de forma aleatória e concentrados longitudinalmente no lado esquerdo do indivíduo inumado. Completavam esta estrutura dois lateres oblíquos na zona da cabeceira formando uma cobertura de duas águas.

Bioantropologia: apesar do mau estado de conservação dos vários elementos ósseos, o esqueleto apresenta uma boa representatividade óssea. $\mathrm{O}$ indivíduo encontrava-se em decúbito dorsal, com membro superior esquerdo fletido sobre o abdómen e a mão sobre o ilíaco direito, e o membro superior direito, bem como os membros inferiores, em extensão. A análise do perfil biológico revelou tratar-se de um indivíduo do sexo feminino (Ferembach, Schwidetzky \& Stloukal, 1980, 1980, Wasterlain, 2000, Bruzek, 2002; Walker, 2008). Com base na morfologia da superfície auricular (Lovejoy $\&$ alii, 1985), na observação da linha de fusão da cabeça do fémur direito 
(Buikstra \& Ubelaker, 1994), e na ausência de fusão da extremidade esternal da clavícula (MacLaughlin, 1990), estamos perante um adulto ainda jovem.

"Mobiliário funerário": o numisma n. ${ }^{-180}$ ligeiramente descentrado, mas não cerceado, equivale a um antoninianus cunhado sob Galieno (253268 d.C.), das séries Providentia ou Providentia Aug(usta), emitidas em Roma entre $260-268$ d.C. ( RIC V-1.270; 276). O anel em prata n. ${ }^{\circ} 181$ repete o tipo IVc de Aquincum (vide Sep. 2, acima). O artefacto em osso n. ${ }^{\mathbf{1}} \mathbf{1 8 2}$ corresponde a um alfinete de cabelo (acus crinalis), impedindo-nos a ausência da extremidade superior de o precisar tipo-cronologicamente. O compasso n. $^{\mathbf{0}} \mathbf{1 8} 3$ foi já objecto de publicação (Cabaço \& alii, 2019), e embora não encerre especial significado crono-tipológico, destaca-se pela sua assimilação ao trabalho artesanal de pormenor (joalharia? bijuteria? trabalho em osso?), sugerida pelos contornos funcionais de um contexto bordalês (Raux, 2016: 42). O recipiente em vidro n.․ 187 , de tonalidade verde-gelo, translúcida, revela afinidades com alguns exemplares de Augst do tipo AR 6o, que revelam semelhanças morfológicas (Rütti, 1991, nºs 1298, 1333). Com uma decoração de dois círculos concêntricos relevados produzidos a buril, com aquele interior opaco, alternados com métopas de traço vertical simples e os topos com outros pequenos ligeiramente oblíquos, obtidos da mesma forma. Tem paralelo exacto num exemplar divulgado por Deus como colectado em 1798 numa sepultura do aro mirobrigense céltico, em Herdade do Raco (Santiago do Cacém), ofertado a Fr. Manuel do Cenáculo, estando hoje em exposição no Museu de Évora (Deus, 2016, p. 64 e 70). A lucerna, no 179 , lacriforme, com disco raiado, é datável para o séc. II e III (?) em Ampúrias (Casas i Genover; Solé i Fusté, 2006). Na cerâmica comum, em pasta quartzo-micácea vermelha, o nํㅜ $\mathbf{1 8 8}$, com pé-de-anel, volta a revelar inspiração no tipo Hayes 3 de terra sigillata africana (ver supra, n⿳ำ 199 , com corpo mais baixo e largo, mais próximo do protótipo africano coevo. Hayes, 1972). Os nos 189 e 190, potinhos de fabrico quartzo-micáceo, laranja e laranja-castanho respectivamente, rico em moscovite, têm paralelos no Norte Alentejano (Nolen, 1985, p. 71, nºs 172-175: referidos em contextos da segunda metade do séc. I e do II d.C.). No centro da Quinta do Rouxinol (225/250-425+ d.C.), o tipo 2.3.4.2 possui curva e contracurva enquanto os $n^{\circ} \mathbf{S}$ 189 e 190 possuem apenas a carena suave (voltaremos infra a esta fisionomia com o $\mathbf{n}^{\mathbf{0}} \mathbf{2 3 0}$ ).
Sepultura 4 - Deposição em coval rectangular, com as paredes laterais interiores revestidas a reboco branco. A presença da sepultura foi sinalizada com lateres dispostos horizontalmente, recobertos por amálgama de pedras calcárias de pequena e média dimensão.

Bioantropologia: A metade esquerda do esqueleto foi destruída, e o antebraço direito afectado. $\mathrm{O}$ indivíduo encontrava-se em decúbito dorsal com o membro superior direito ligeiramente flectido com a mão sobre o ilíaco direito, e os membros inferiores estendidos. Trata-se de um indivíduo adulto feminino (Wasterlain, 200o; Bruzek, 2002; Walker 2008), com uma idade à morte superior a 30 anos, a avaliar pelo estágio de fusão epifisária da extremidade esternal da clavícula (MacLaughlin, 1990).

"Mobiliário funerário": Na sepultura 4 recorre-se a vidro, terra sigillata, lucerna e cerâmica comum. O gobelet $\mathrm{n}$ 을 210 não tem paralelo aproximado. Com pé maciço muito baixo tem corpo troncocónico e colo cilíndrico altos. A parede tem decoração plástica com cordões de vidro que desenham formas oblongas verticais (com segmento simétrico aposto à base) separadas por bastões lineares verticais. $\mathrm{O}$ n을 212, com marcas de polimento forte na parede, volta a integrar-se na forma genérica da AR 6o, com semelhanças evidentes ao no 196 (supra), apesar do corpo agora mais verticalizado. Neste sentido, aproxima-se igualmente do tipo $\mathrm{AR} 38$, que termina no terceiro quartel do séc. III (Rütti, 1991), bem como do copo de paredes finas e base maciça, datado em Bracara Augusta entre os séc.s II e IV (Cruz, 2009). O no 213 é um exemplar completo de terra sigillata africana A, tipo Hayes 16/Hayes 15, ou seja, fundindo as duas morfologias, com o corpo baixo da primeira e o bordo biselado da segunda, que a data a partir de 250 d.C. (Bonifay, 2004). O no 214 integra-se novamente na fase final de desenvolvimento das lucernas de disco no séc. III (Quaresma, 2018), com moldura larga a separar orla e disco curvos, planos (ver supra nos 224 e 198). Em cerâmica comum, o no 202 é um pote alto de bordo curto exvertido, com pasta castanho-vermelha, quartzo-micácea. Segundo Cézer Santos (2011, p. 81-82: tipo 2.2.4.1), é uma forma muito comum, com paralelos em São Cucufate e na Península de Lisboa. Todos os exemplares da Quinta do Rouxinol (225/250-425+ d.C.) são do fabrico C (matriz quartzo-micácea, de tom vermelho-laranja). 
Sepultura 5 - Deposição de ataúde - numerosos pregos assinalados (Cabaço \& alii, 2017b, p.35) no interior de coval sub-rectangular.

Bioantropologia: Não obstante o mau estado de conservação dos vários elementos ósseos, e a fraca representatividade óssea, os pequenos fragmentos recuperados de crânio, da escápula direita, de costelas e dos membros inferiores, sugerem tratar-se de um indivíduo não-adulto. Por forma a obter um intervalo etário mais específico, e dada a natureza fragmentaria deste individuo, procedeu-se a uma comparação com os não adultos identificados na Praça da Figueira em 1999-2001, de idêntica cronologia (Casimiro, Silva \& Alves-Cardoso, no prelo). Os resultados obtidos a partir desta comparação apontam para um individuo com menos de 12 meses de vida. O nível de fragmentação e afectação deste enterramento, impossibilitou a observação no que respeita à deposição do individuo.

"Mobiliário funerário": A sepultura 5 apresenta uma menor variedade de tipologias que a anterior. Para além de um numisma no 221, um "bronze" exausto, regista-se novamente um vidro, $\mathrm{n}$ - 223, do tipo AR 6o (250+ d.C.: Rütti 1991), mas com pé-de-anel simples e depressões verticais oblongas na parede. A sua fisionomia é próxima igualmente do tipo AR 53, datado a partir de final do séc. II d.C. (Rütti, 1991), enquanto que em Bracara Augusta se apontam algumas relações de copos de base maciça com o tipo Isings 34 e as produções do séc. II, III e IV d.C. (Cruz, 2009). Na Gallia, alguns fundos em disco de gobelets assim decorados, estão datados do séc. III (Foy, 2010, p. 361, nos 668-670). A lucerna no 224 inclui-se novamente na família das lucernas de disco, com ombro e disco lisos e moldura larga a separar ambos, uma característica que marca a fase final das lucernas de disco, no séc. III d.C., como acontece em sepulturas de c. 250 d.C. de Almoínhas (Quaresma, 2018). Na cerâmica comum, o no 226 é um potinho de fabrico calcário, com paralelos formais e de fabrico no centro produtor da Quinta do Rouxinol, entre 225-25o e $425+$ d.C.. O tipo 2.3.4.2 possui, contudo, curva e contracurva, enquanto o no 226 possui apenas a carena suave com canelura larga. O fabrico D3a (matriz calcária, branca-creme) é, porém, secundário neste tipo, fabricado sobretudo em matriz quartzo-micácea de pasta vermelha e alaranjada (Santos, 2011, p. 85 e est. XXV). O no 225 é um pote de bordo curto exvertido, com pasta castanho-clara, quartzo-micácea. Com altura de 18omm conforma versão grande dos potes gráceis do Norte Alentejano (Nolen, 1985, p.118).

Sepultura 6 - Deposição de ataúde (alguns pregos) no interior de coval sub-rectangular, extenso. Parte superior não preservada.

Bioantropologia: Apenas foram recuperados fragmentos dos membros inferiores. A posição destes elementos ósseos sugere que o individuo foi depositado em decúbito dorsal, com os membros inferiores em extensão, ligeiramente inclinados para o lado direito. A observação da maturação óssea sugere tratar-se de um indivíduo adulto, muito provavelmente do sexo feminino (Ferembach, Schwidetzky \& Stloukal, 1980, 1980; Wasterlain, 2000).

"Mobiliário funerário": A sepultura 6 é o contexto com o maior número de exemplares, incluindo dois numismas, anel, lucerna e um leque abrangente de cerâmica comum. Os numismas no 229 A e 229 B equivalem, respectivamente, a um bronze com efígie radiada muito gasto e um antoninianus de Galieno (253-2698 d.C.). O anel s/no de [661] é de novo do tipo Aquincum IVc (vide supra, sepulturas 2 e 3 ). A lucerna no $\mathbf{2 2 8}$ revela alguns pormenores novos de transição final para a futura Dressel 28, mas ainda com orla lisa. Para além da moldura larga a separar orla e disco, o bico já é cordiforme, como será na forma mais tardia referida (Bussière, 200o). No disco, sobremoldado (como acontece em todas as lucernas deste artigo), Helios com Diana Hecate, parecendo tratar-se de uma reprodução de um modelo itálico campano (Catalano, 1953, p. 4, fig.1).

$\mathrm{Na}$ cerâmica comum de fabrico, o fabrico calcário está representado pelo no $\mathbf{2 3 0}$, com carena suave e canelura larga. A morfologia e o fabrico, como se disse supra, tem paralelos no centro produtor da Quinta do Rouxinol - 225/250-425+ d.C. (Santos, 2011, p. 85 e est. XXV - o tipo 2.3.4.2 que possui curva e contracurva, tem fabrico minoritário de matriz calcária). No Norte Alentejano, alguns contextos da segunda metade do séc. I e do II d.C. apresentam exemplares similares (Nolen, 1985, p. 71, nºs 161-177). O no 227 é um potinho de fabrico calcário, creme-rosa, com parede curva, lisa (não tem bordo nem colo conservados), com relativas semelhanças ao $\mathrm{n}$ - $\mathbf{2 1 6}$ (ver supra), mas de parede mais curva. No fabrico de matriz quartzo-micácea, o no 233 é uma terceira imitação, algo distante morfologicamente (parede muito rectilínea e, novamente, ausência de pé-de-anel) da Hayes 3 de T.S. Clara africana (ver 
supra). O no 234 é um potinho de fabrico quartzo-micáceo, laranja, rico em moscovite, semelhante ao no 230, mas agora com a curva e contracurva conhecida no Norte Alentejano (Nolen, 1985, p. 71, nos 172-175: em contextos da segunda metade do séc. I e II d.C.) e no Porto dos Cacos (Santos, 2011). O no 231 está muito próximo do $n^{\circ}$ 234, também com canelura acima ma meia-pança. Exibe, porém, decoração espatulada de linhas oblíquas paralelas em série, frequente nestas gamas de cerâmica comum na Península de Lisboa e no Norte alentejano. Esta mes-

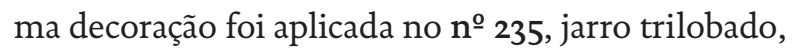
com canelura larga acima da carena suave e espatulado oblíquo entre a canelura e o colo, em fabrico quartzo-micáceo, castanho-claro. Neste caso, sem paralelos na Quinta do Rouxinol, mas com alguma semelhança formal, embora de bordo mais comprido e sem espatulado, no Norte Alentejano (séc. I e inícios do II: Nolen, 1985, p. 6o, nํ130: fabrico G: laranja, fino), e em Conimbriga, de pastas finas e com espatulado (Alarcão, 1975, nº 504 e 579). O no 232 é uma bilha pequena, sem bordo conservado.

Sepultura 7 - Sepultura em caixa estruturada por fundo argamassado, paredes em argamassa com elementos pétreos e cerâmica e um dos topos com later argamassado. Cobertura visível, de lateres e imbrex dispostos em telhado de duas águas na zona da cabeceira e o restante por um later horizontal travando uma imbrex, argamassados lateralmente.

Bioantropologia: o esqueleto encontrava-se em muito mau estado de conservação, sendo apenas recuperados fragmentos do crânio, costelas e vértebras. Com base na morfologia óssea foi possível estimar tratar-se de um indivíduo não adulto. Tal como aconteceu no caso da sep.5, por forma a obter um intervalo etário mais específico, procedeu-se a uma comparação com os indivíduos não adultos identificados na Praça da Figueira em 1999-2001, recorrendo a fragmentos de costelas e de vertebras. Os resultados obtidos a partir desta comparação apontam para um individuo com menos de 6 meses de vida. "Mobiliário funerário": Sem mobiliário funerário.

Sepultura 8 - Coval com cobertura em telhado laterício de duas águas, travado no topo por fragmento de later em cutelo (preservada apenas a parte correspondente à cabeceira). O contexto foi profundamente afectado por uma construção contemporânea.
Bioantropologia: não foram identificados vestígios ósseos no interior da sepultura.

"Mobiliário funerário": Identificou-se apenas um pote biansado no topo, não se apurando a sua relação com a disposição do inumado. Com o n⿳o 216, será um potinho em pasta quartzo-micácea semelhante aos nํㅗ 226 (supra), 190, 230 e 227 (infra).

Sepultura 9 - Coval ovalado, no interior do qual se depositou um ataúde (pregarias). Cobertura não preservada.

Bioantropologia: devido ao grau de afectação desta sepultura, apenas foi possível recuperar fragmentos dos membros inferiores. Terá sido depositado em decúbito dorsal, a avaliar pela posição dos elementos ósseos identificados. A observação da maturação óssea revela tratar-se de um indivíduo adulto, muito provavelmente do sexo masculino (Wasterlain, 200o).

"Mobiliário funerário": não identificado dada a afectação da sepultura.

Sepultura? 1o - Trata-se de um revestimento parietal e do fundo de coval com laterício, muito marginalmente preservado sob as estruturas do prédio, e que, a despeito de não se terem encontrado evidencias funerárias categóricas, deverá corresponder a uma sepultura muito destruída.

Sepultura? 11 - Coval sub-rectangular, em tudo idêntico aos seguramente funerários documentados no local. O depósito de preenchimento do seu fundo nada revelou de evidências funerárias. Cobria-o um depósito de pedra de pequena dimensão, que revelou escassos fragmentos cerâmicos, alguns de cronologia medieval/moderna. Pode, todavia, corresponder a uma sepultura violada.

\section{DISCUSSÃO}

O núcleo funerário das Portas de Santo Antão apresenta algumas características singulares, nomeadamente a boa gestão do espaço, dado não se verificarem cerceamentos ou sobreposições de acções sepulcrais, a sincronia, aqui refinada para o último terço do séc. III d.C. (possivelmente centrada nas décadas de 260 a 280 d.C.), bem como evidentes afinidades constatadas nos "mobiliários funerários", elementos que no seu conjunto se destacaram desde a primeira hora e que levaram alguns dos autores a 
propor preliminarmente "sugerirem-se explicações de índole cultural e/ou de parentesco dos inumados, que só outro tipo de análises poderia sustentar" (Cabaço \& alii, 2017a, p. 1249).

De outro modo, e sintomaticamente, o espaço utilizado no período em causa não revelou quaisquer indícios de práticas fúnebres anteriores, ao contrário do que fora antes constatado nos núcleos da Praça da Figueira (Silva, 2005) e Encosta de Santana (Muralha, Calado \& Costa, 2002), sujeitos a um faseamento mais rico e complexo. Este aspecto assume relevância, por implicitamente acarretar outro tipo de usos anteriores do terreno, podendo significar, em sentido inverso, um fenómeno de expansão fúnebre, já documentado nos outros núcleos mencionados da Necrópole Noroeste de Olisipo, da Praça da Figueira, Encosta de Sant 'Ana (Muralha, Calado \& Costa, 2002) e, eventualmente, da Calçada do Lavra. Atentando à representatividade do perfil biológico presente no núcleo, e a despeito das óbvias limitações que impõem a exiguidade da amostra e o seu mau estado de preservação, a análise comprovou a heterogeneidade desta, visto ser composta por indivíduos de ambos os sexos e de diferentes grupos etários. Não deverá ser valorizada aqui a relação de sexo (4 femininos / 2 masculinos). Todavia, a presença dos dois infantes deve ser aqui destacada pela discrepância entre ambos: no indivíduo classificado como "com menos de 6 meses" é evidente a ausência de "mobiliário associado" (Sep. 7), por contraste com aquele classificado como "com menos de 12 meses" (Sep. 5), onde a existência de ataúde e a composição do "mobiliário funerário" em nada o distinguem dos restantes indivíduos adultos.

O "mobiliário funerário", conjugado com os dados do perfil biológico dos indivíduos, não revelou diferenças significativas entre estes, antes similitude. Assinala-se neles a assídua presença de numismas, lucernas, objectos destinados ao consumo alimentar e à sua conservação (líquidos e sólidos; predominantemente depostos após a colocação do ataúde, no exterior deste, com maior incidência numa zona reservada do coval junto aos pés, mas não só- Seps.1 e 2), com dois casos em que a olla foi usada para conter a lucerna. Destacam-se somente destas observações os elementos de adorno pessoal (anéis de prata tipo Aquincum IVc e acus crinalis), invariavelmente associados a indivíduos adultos femininos.

Sendo admissível no núcleo das Portas de Santo Antão a utilização de um mesmo espaço funerário por parte de um grupo humano de relativa homogeneidade (cultural, social, ...), só ulteriores análises poderão eventualmente vir a esclarecer de forma categórica a natureza das suas afinidades, constituindo, de qualquer das formas, um relevante repositório das práticas funerárias a uso num espaço de tempo confinado do último terço do séc. III d.C.

\section{BIBLIOGRAFIA}

ALARCÃO, Jorge de (1975) - Fouilles de Conimbriga. V (La Céramique Commune Locale et Régionale). Paris: Difusion E. de Boccard.

BONIFAY, Michel (2004) -Études sur la céramique romaine tardive d'Afrique. Oxford: Archaeopress (Col. British Archaeological Reports, International Series. 1301).

BRUZEK, Jaroslav (2002) - A method for visual determination of sex, using the human hip boné. American Journal of Physical Anthropology. pp. 157-168.

BUIKSTRA, Jane E.; UBELAKER, Douglas H. (1994) Standards for data collection from human skeletal remains: proceedings of a seminar at the Field Museum of Natural History. Fayettevile, Arkansas, Arkansas Archeological Survey.

BUSSIÈRE, Jean (200o) - Lampes antiques d'Algérie. (Monographies Instrumentum; 16). Éditions Monique Mergoil.

CABAÇO, Nelson; SARRAZOLA, Alexandre; SILVA, Rodrigo Banha da; CARVALHO, Liliana Matias; LOURENÇO, Marina (2017a) - O espaço de necrópole Romana das Portas de Santo Antão, Lisboa. In Arqueologia 2017. Estado da Questão. Lisboa: Associação dos Arqueólogos Portugueses, pp. 1243-1254.

CABAÇO, Nelson; SARRAZOLA, Alexandre.; REIS, Helena; LOURENÇO, Marina (2017b) - Relatório Final de Trabalhos Arqueológicos, Projeto de Requalificação Urbana Intervenção Arqueológica Rua das Portas de Santo Antão 84/9o Lisboa. Cruz Quebrada, ERA Arqueologia.

CABAÇO, Nelson; LOURENÇO, Marina; SILVA, Rodrigo Banha da (2019) - O compasso do espaço de necrópole romana das Portas de Santo Antão, Lisboa. In Revista Apontamentos de Arqueologia e Património, $\mathrm{n}^{\circ}{ }^{13}$. Lisboa: NIA, Era-Arqueologia S.A., pp. 47-54.

CARDODO, Hugo; SAUNDERS, Shelley (2008) - Two arc criteria of the ilium for sex determination of immature skeletal remains: a test of their accuracy and an assessment of intra an inter observer error. Forensic Science International,178, pp. 24-29.

CASAS i GENOVER, J.; SOLE i FUSTÉ, V. (2006) - Llànties romanes d'Empúries. Materiales augustals i alto-imperials. Girona: Museu d' Árqueologia de Catalunya (Monografies Emporitanes; 13). 
CASIMIRO, Silvia; SILVA, Rodrigo Banha da; ALVES-CARDOSO, Francisca (no prelo) - 'et sepultus est'. A multiplicidade da morte na Necrópole Noroeste de Olisipo (séc. I a IV d.C.). In A Morte em Lisboa: novos dados, novas problemáticas. Comissão de Estudos Olisiponenses, Museu Arqueológico do Carmo. Lisboa.

CATALANO, Virgilio (1953) - La lucerna di Civitá. In Samnium, Napoli: Instituto della Stampa, 35, pp. 3-8.

CRUZ, Mário da (2009) - O Vidro Romano no Noroeste Peninsular: um olhar a partir de Bracara Augusta. Tese de doutoramento. Braga: Universidade de Minho.

DEUS, Manuela de (2016) - Quando o objecto desafia a curiosidade: A actividade arqueológica de Cenáculo e seus colaboradores em Santiago do Cacém. In Dom Frei Manuel do Cenáculo Itinerários por Santiago do Cacém. Santiago do Cacém: União das Freguesias de Santiago do Cacém, Santa Cruz e São Bartolomeu da Serra, pp. 165-183.

FACSÁDY, Annamária R.; VEREBES, Anett (2009) - Analysis of Roman Bronze Finger Rings from Aquincum. In Materials and Manufacturing Processes, 24:9. London: Taylor \& Francis Group LLC, pp. 993-998.

FEREMBACH, D.; SCHWIDETZKY, I.; STLOUKAL, M. (1980) - Recommendations for age and sex diagnoses of skeletons. Journal of Human Evolution, 9. pp. 517-549.

FOY, Danièle (2010) - Les verres antiques d'Arles: La collection du Musée Dépertemantal. Arles Antique. Paris: Éditions Errance.

HAYES, John W. (1972) - Late Roman Pottery. Londres: British School at Rome.

ISINGS, Clasina (1959) - Roman glass from dated finds. Groningen e Jacarta: Academiae Rheno - Traiectinae Instituto Archaeologico (colArchaeologia Traiectina, II).

LOVEJOY, C. Owen; MEINDL, Richard; PRYZBECK, Thomas; MENSFORTH, Robert (1985) - Chronological metamorphosis of the auricular surface of ilium: new method for the determination of adult skeletal age at death. American Journal of Physical Anthropology, 68. pp. 15-28.

MACLAUGHLIN, S. M. (1990) - Epiphyseal Fusion at The Sternal End of the Clavicle in a Modern Portuguese Skeletal Sample. Antropologia Portuguesa, 8. pp. 59-68.

MURALHA, João; COSTA, Cláudia, CALADO, Marco (2002) - Intervenções Arqueológicas na Encosta de Sant'Ana (Martin Moniz, Lisboa) in Al-Madan. Almada 2ª série $\mathrm{n}^{0}$ 11, pp. 245-246.

NOLEN, J. S. (1985) - Cerâmica comum de necrópoles do Alto Alentejo. Lisboa: Fundação da Casa de Bragança.

PINTO, I. Vaz (2003) - A cerâmica comum das villae romanas de São Cucufate (Beja). Lisboa: Universidade Lusíada Editora. (Colecção Teses).
QUARESMA, José Carlos (2018) - Transição estratigráfica em Almoínhas (Loures, Portugal): evolução das importações finas na Lusitania entre c.10o e c.32O d.C.. CIRA Arqueologia. 6, p. 199-230.

QUARESMA, José Carlos (no prelo) - The $3^{\text {rd }}$ century AD in motion: new proposals on morphologic-and-chronological lamps evolution (Disc-type, Dressel 28, Dressel 27, Dressel 30 and Disc-type derived). Terracota lamps in Archaic, Classical, Hellenistic, Roman and Early Byzantine Anatolia: production, use, typology and distribution. An international symposium. May 16-17, 2019, Izmir, Turkey.

RAUX, Stéphanie (2016) - Jambes de compas du Haut-Empire portant des graduations de mesure : un exemplaire sur le site de l'Auditorium à Bordeaux (F, Gironde). In Bulletin Instrumentum, 43. S/1, Association Instrumentum, p.42.

RICVa= MATTINGLY, Harold; SYDENHAM, Edward Allen; WEBB, Percy H. (1927) - Roman Imperial Coinage, vol. 5, Part.1, Valerian to Florian (253-276). London: Spink.

RODRÍGUEZ MARTÍN, F. G. (2002) - Lucernas romanas del Museo Nacional de Arte Romano (Mérida). Madrid: Ministerio de Educación, Cultura y Deporte (Monografías Emeritenses; 7).

RÜTTI, Beat (1991) - Die Römischen Gläser aus Augst und Kaiseraugst, vol. II, Katalog und Tafeln. Augst: Museen und Archäologie des Kantons Basel- Landschaft (col. Forschungen in Augst, 13).

SANTOS, Cézer Renato (2011) - As cerâmicas de produção local do centro oleiro romano da Quinta do Rouxinol (Setúbal, Portugal) (Dissertação de Mestrado em Arqueologia). Lisboa: Faculdade de Letras da Universidade de Lisboa (policopiado).

SILVA, Rodrigo Banha da (2005) - As "marcas de oleiro" em terra sigillata da Praça da Figueira (Lisboa): uma contribuição para o conhecimento da economia de Olisipo (séc. I a.C.séc. II d.C.) (Dissertação de Mestrado). Braga: Universidade do Minho, Instituto de Ciências Sociais (policopiado).

WALKER, Phillip L. (2005) - Greater sciatic notch morphology: sex, age, and population differences. American Journal of Physical Anthroplogy, 127(4). pp. 385-391.

WALKER, Phillip L. (2008) - Sexing skulls using discriminant function analysis of visually assessed traits. American Journal of Physical Anthroplogy, 136(1). pp. 39-50.

WASTERLAIN, Rosa Sofia (200o) - Morphé: análise das proporções entre os membros, dimorfismo sexual e estatura de uma amostra da colecção de esqueletos identificados do Museu de Antropologia da Universidade de Coimbra. Dissertação de mestrado em Evolução Humana. Departamento de Antropologia. Coimbra: Universidade de Coimbra.

WHITE, Tim., FOLKENS, Peter (2005) - The human bone manual. Amsterdam: Academic Press. 

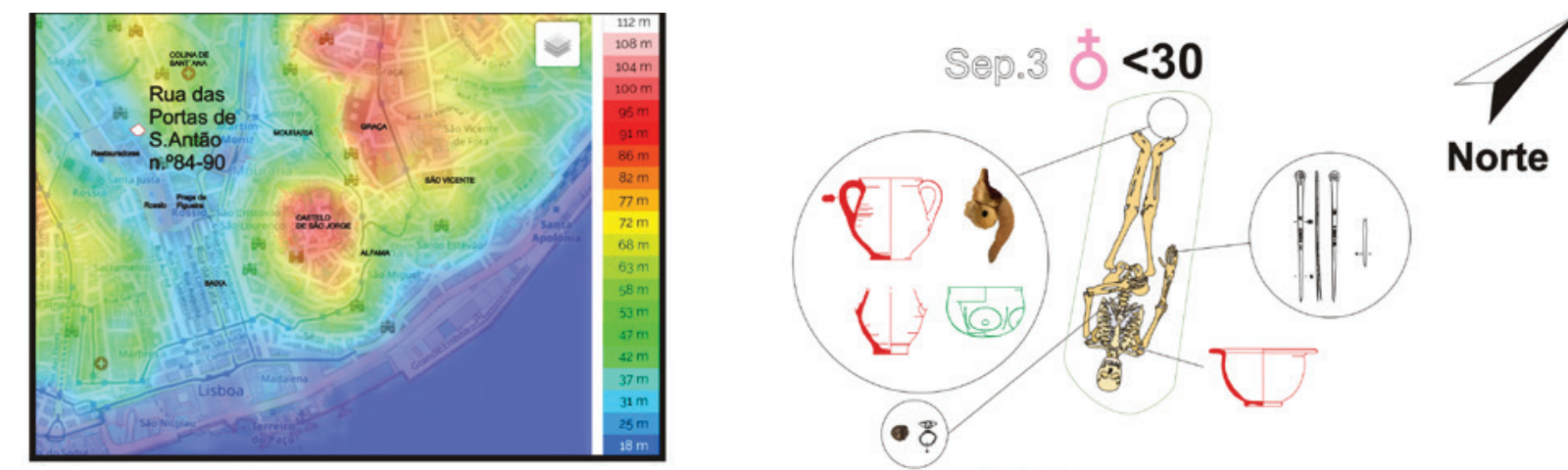

Norte

Sep.80?
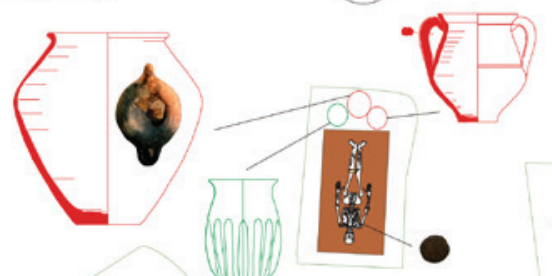

Sep.7 $0<6 \mathrm{~m}$

Sep.5

( $<<12 \mathrm{~m}$

11 ?

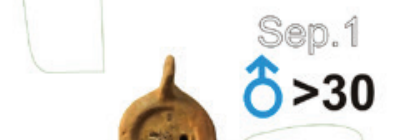

(5)
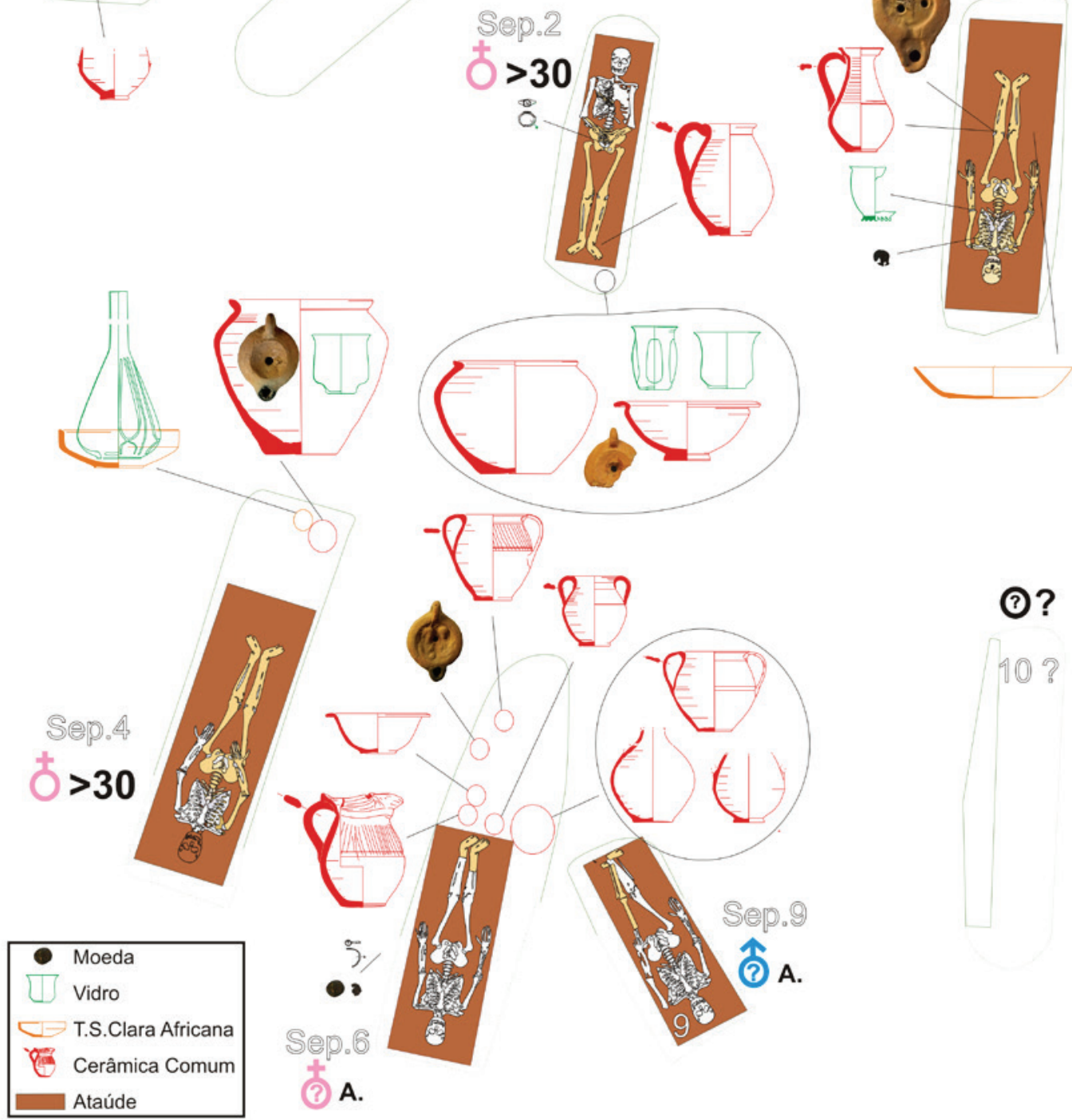

ㅇ? 


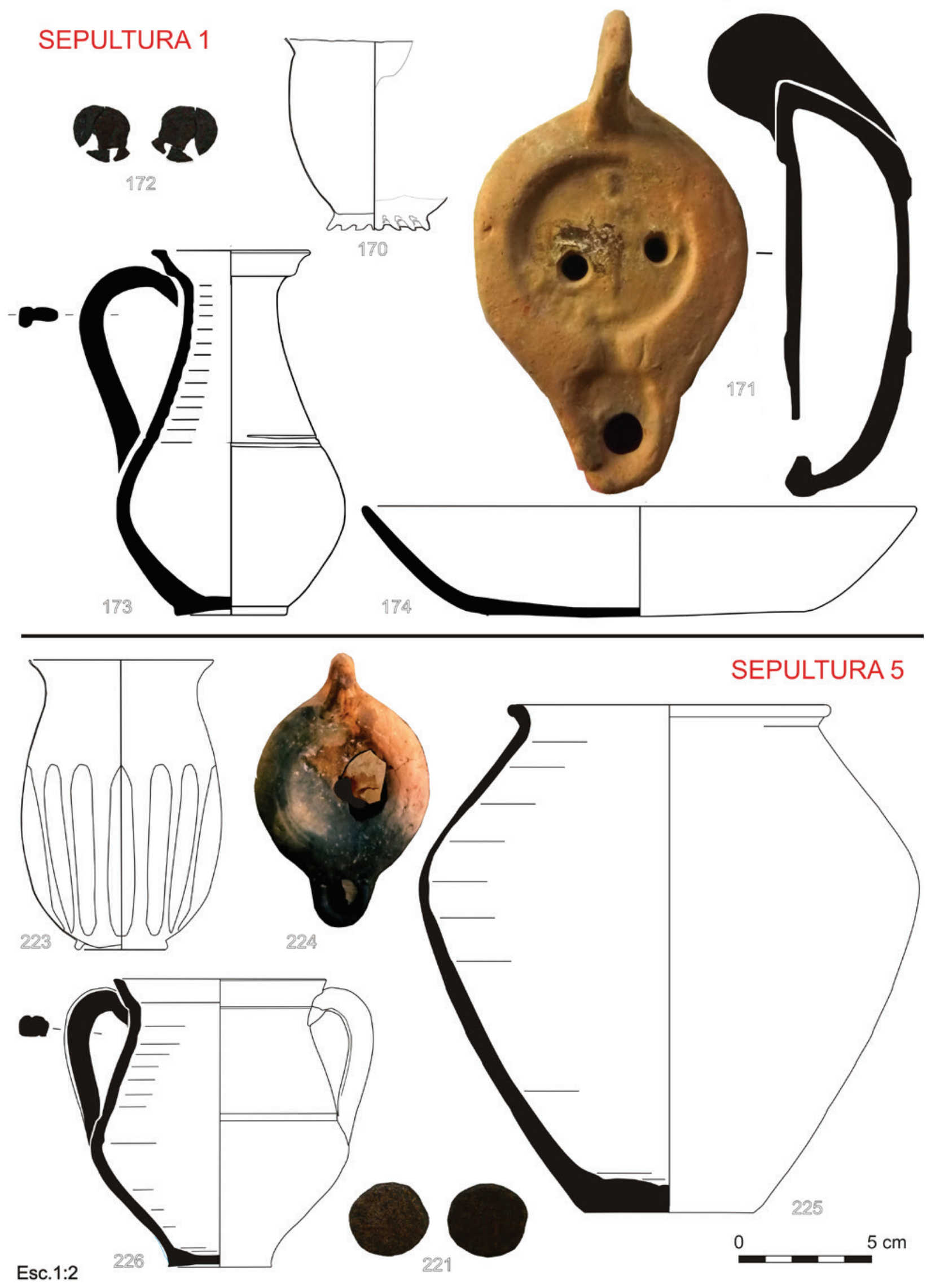

Figura 2 


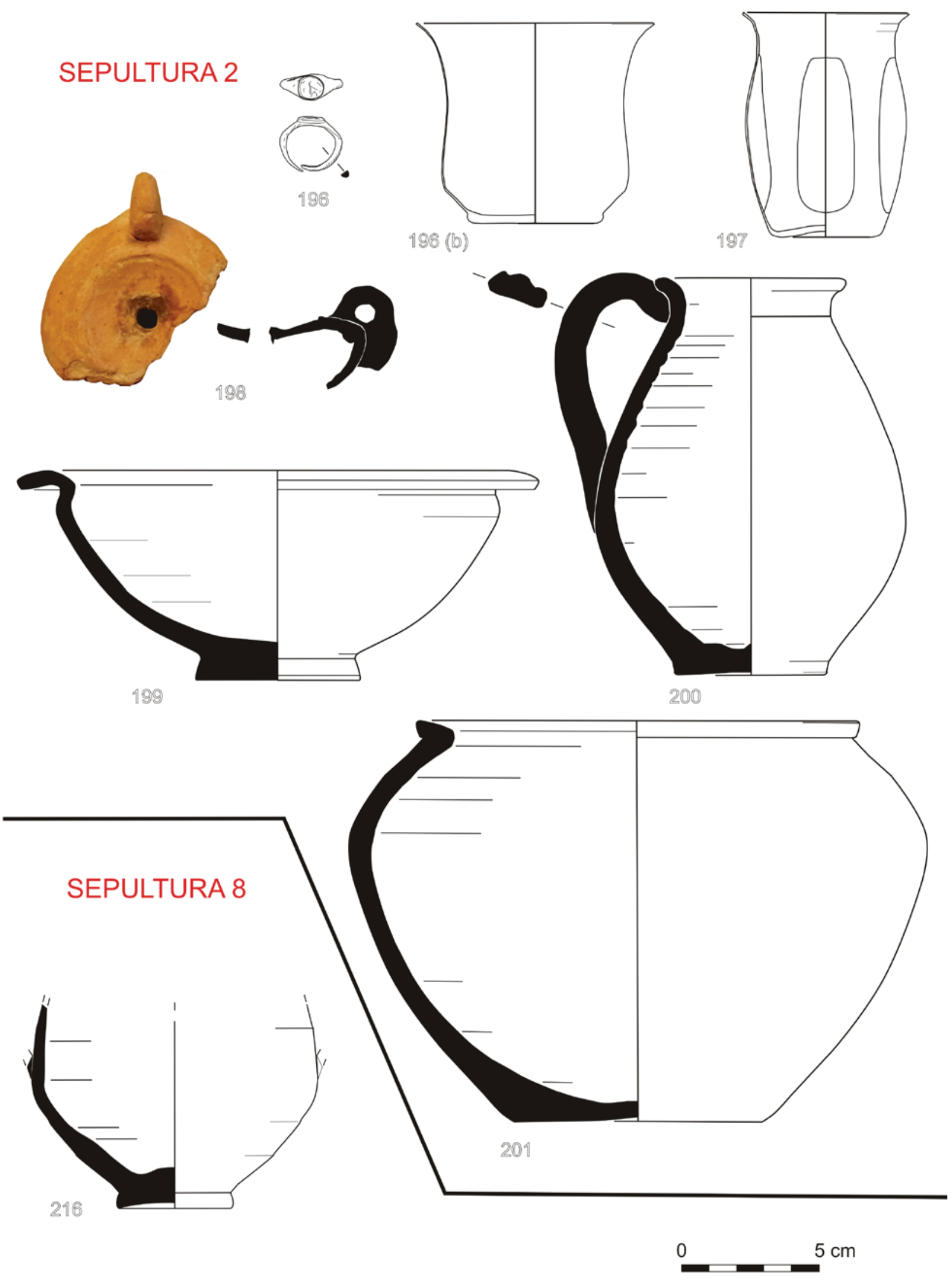

Esc.1:2

Figura 3 


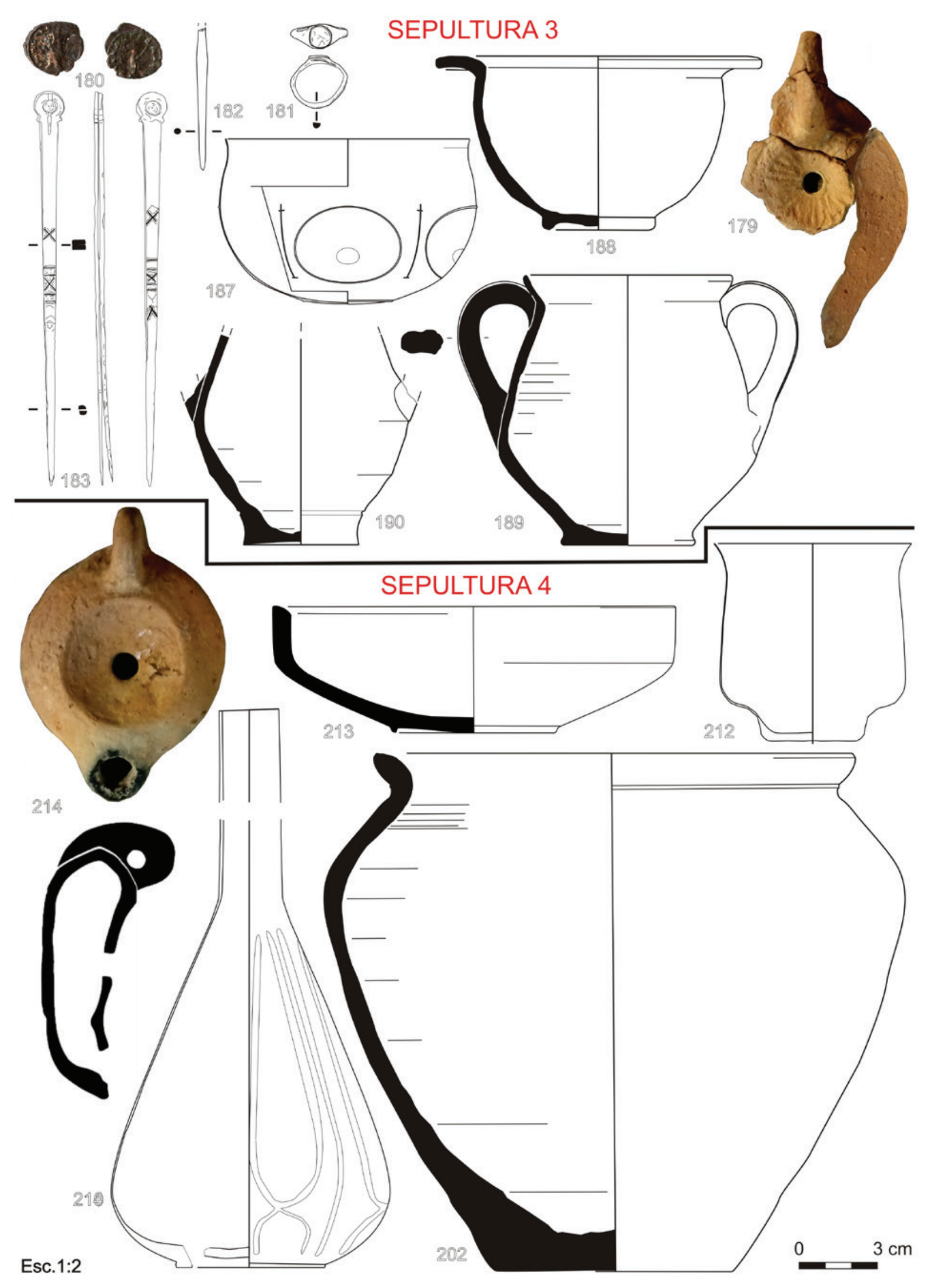

Figura 4 


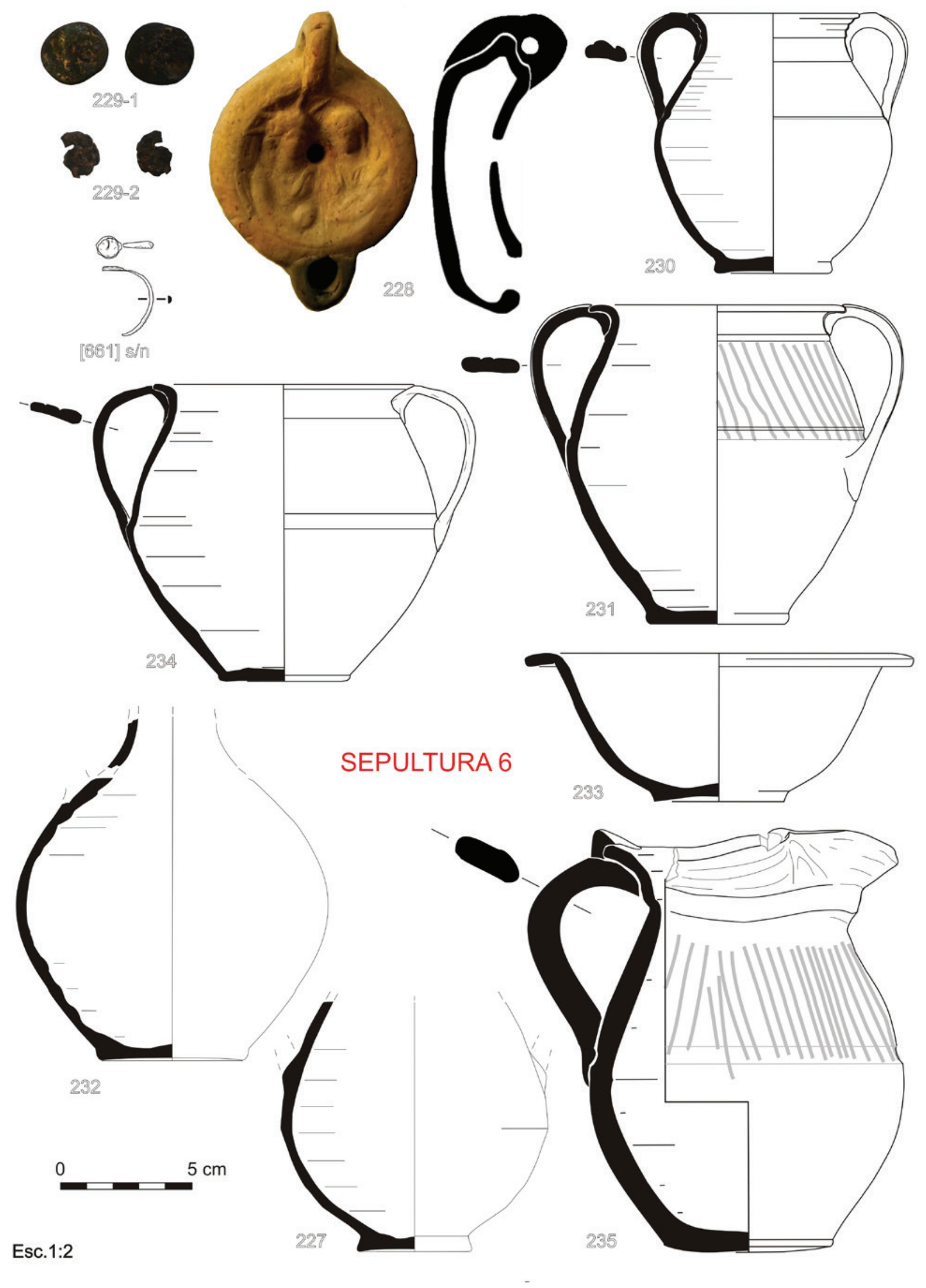

Figura 5 


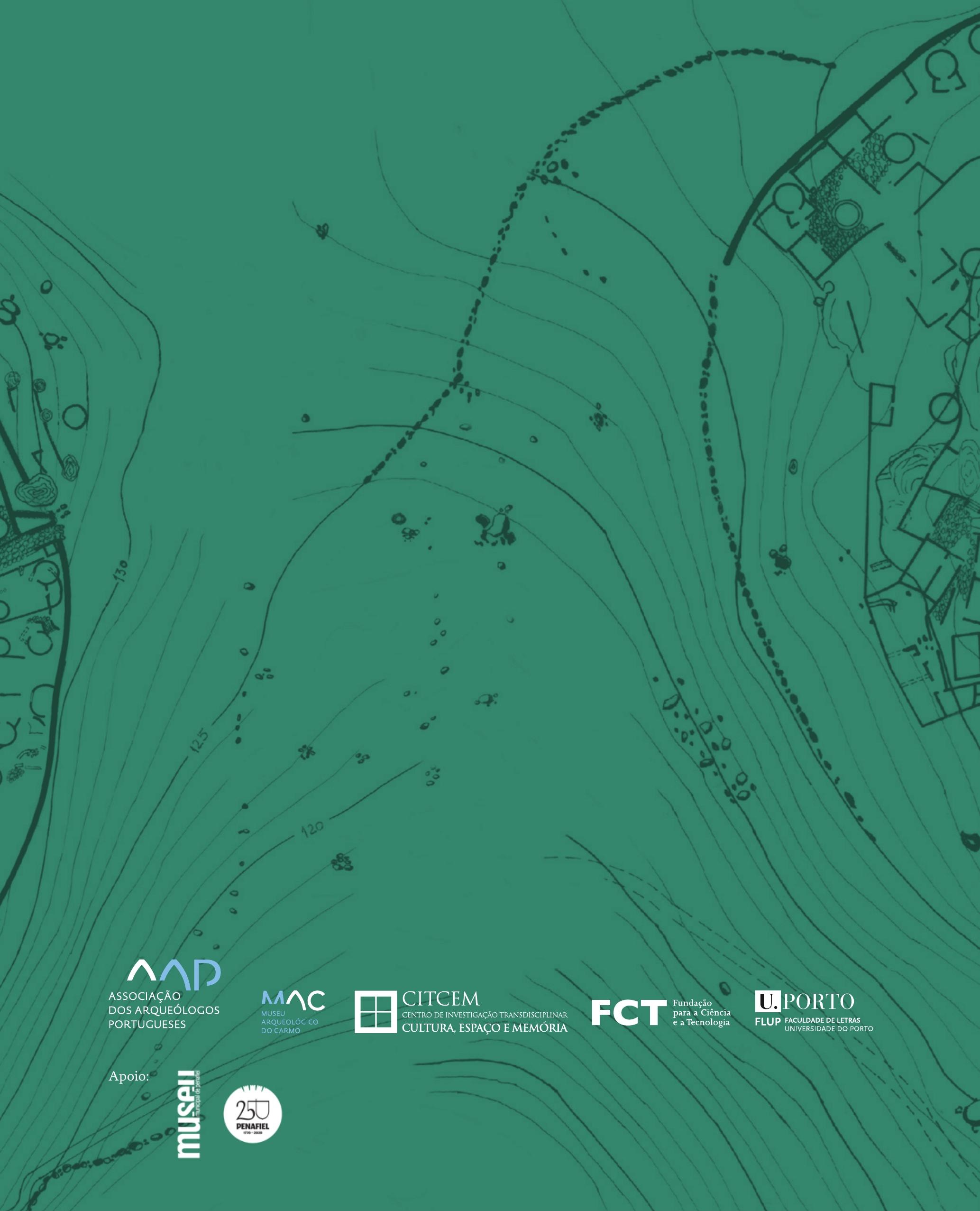

